\title{
Digestibilidade do fósforo em dietas como estratégia nutricional para redução de efluentes da tilapicultura
}

\author{
[Digestibility of phosphorus in feed as a nutritional strategy for reduce of \\ effluents from tilapia culture] \\ G.W. Bueno ${ }^{1}$, A. Feiden ${ }^{2,3}$, D.H. Neu $^{2,3}$,T.A. Lui $^{2,3}$, N. Wächter, ${ }^{2,3}$, W.R. Boscolo ${ }^{2,3}$ \\ ${ }^{1}$ Ministério da Pesca e Aquicultura - MPA - Brasília, DF \\ ${ }^{2}$ Universidade Estadual do Oeste do Paraná - UNIOESTE - Toledo, PR \\ ${ }^{3}$ Grupo de Estudos de Manejo na Aquicultura - GEMAQ - Toledo, PR
}

\section{RESUMO}

Avaliou-se a digestibilidade do fósforo em dietas isoproteicas e isoenergéticas contendo $28 \%$ de proteína bruta e $3000 \mathrm{kcal}$ de ED/kg com porcentagens de 0,8 e 1,2\% de fósforo total para juvenis de tilápia-donilo (Oreochromis niloticus). Os parâmetros de qualidade da água apresentaram diferenças significativas $(\mathrm{P}<0,05)$ para o fósforo total, ortofosfato, $\mathrm{DBO}_{5}$ e condutividade. A digestibilidade das dietas foi de $75,3 \%$ para os peixes alimentados com $0,8 \%$ de fósforo total e de 77,5\% para os alimentados com $1,2 \%$ de fósforo total. As taxas de eficiência da absorção do fósforo foram de 74,8\% e 76,3\% para as tilápias alimentadas com $0,8 \%$ e $1,2 \%$ de fósforo, respectivamente. O aumento do percentual de $0,4 \%$ de fósforo na dieta levou ao acréscimo de 55\% de fósforo na água. Dessa forma, a utilização de valores abaixo de $0,8 \%$ de fósforo total é uma estratégia que auxilia na redução do impacto causado pelos efluentes oriundos da criação de peixes, sem comprometer a eficiência do aproveitamento das dietas pelas tilápias.

Palavras-chave: aquicultura sustentável, capacidade suporte, fósforo, manejo nutricional, Oreochromis niloticus

\begin{abstract}
The objective of this study was to evaluate the digestibility of phosphorus in isonitrogenous and isocaloric diets containing $28 \%$ crude protein and $3000 \mathrm{kcal} \mathrm{DE} / \mathrm{kg}$ at different levels of total phosphorus, $0.8 \%$ and $1.2 \%$, in Nile tilapia juveniles (Oreochromis niloticus). The water quality parameters presented significant differences $(P<0.5)$ for total phosphorus, orthophosphate, $\mathrm{BOD}_{5}$ and conductivity. The digestibility of diets was $75.3 \%$ for fish fed $0.8 \%$ total phosphorus and $77.5 \%$ for treatment with $1.2 \%$ total phosphorus. It was observed that the efficiency rate in phosphorus absorption among the treatments was 74.3 and $76.3 \%$ for tilapia fed $0.8 \%$ and $1.2 \%$ phosphorus, respectively. It can be concluded that a percentage increase of $0.4 \%$ phosphorus in tilapia diets contributes to the increase of $55 \%$ of phosphorus in water and the lower phosphorus input in the diet can be a nutritional strategy to be practiced. Thus, it will help to reduce the impact caused by effluents from fish farming, without lowering the efficiency of tilapia diet utilization.
\end{abstract}

Keywords: sustainable aquaculture, carrying capacity, phosphorus, Oreochromis niloticus, nutrient management

\section{INTRODUÇÃO}

O Brasil possui cerca de 40 espécies de peixes de água doce potenciais de cultivo (Godinho, 2007), sendo a mais estudada e produzida a tilápia-do- nilo (Oreochromis niloticus). Sua produção no país aumentou $105 \%$ em apenas sete anos e atualmente está em torno de 132 mil toneladas/ano, o que representa $32 \%$ da produção de pescados cultivados (MPA, 2010). Esta

Recebido em 8 de agosto de 2011

Aceito em 22 de novembro de 2011

Email:guilhermezoo@hotmail.com 
espécie é criada em diferentes latitudes, sob os mais diversos sistemas de produção, abrangendo baixos ou sofisticados níveis tecnológicos (Neves et al., 2009). Tem como características invejáveis a rusticidade ao manejo, carne saborosa, eficiência zootécnica e excelente aceitação pelo mercado consumidor (Stickney, 1997; Faria et al., 2002; Boscolo et al., 2005).

Se, de um lado, estas projeções de crescimento produtivo e, consequentemente, a utilização dos recursos hídricos trarão aos atores da atividade diversos benefícios, por outro, gera obrigações que devem ser cumpridas para a produção de peixes, podendo, ainda, o empreendedor ser responsabilizado por sua conduta em relação ao meio ambiente e aos recursos hídricos, de acordo com os critérios estabelecidos pelas leis vigentes.

Geralmente, em sistemas intensivos aquícolas com tanques-rede utilizam-se 80, 120 ou até acima de $300 \mathrm{~kg} / \mathrm{m}^{3}$ de peixes. Muitas vezes, esta biomassa produtiva não é dimensionada de acordo com o limite aceitável ou assimilável pelo ecossistema aquático. Dessa forma, ultrapassa a capacidade de suporte do ambiente podendo causar a poluição dele (Amirkolaie, 2011). Alves e Baccarin (2005) informaram que $66 \%$ do fósforo aportado pelo arraçoamento intensivo vão para o sedimento, $11 \%$ ficam dissolvidos na água e $23 \%$ são incorporados no peixe em cultivo.

A principal contribuição com o input de fósforo no ambiente aquático pelos sistemas de cultivo de peixes é por meio de rações e, consequentemente, da excreção dos animais (Odum e Barrett, 2007). Portanto, o fósforo pode contaminar meios aquáticos e causar o crescimento exacerbado de algas, além de elevar a demanda bioquímica de oxigênio, causando diminuição do oxigênio presente na água e alterações no meio, levando à morte de peixes e outros animais (Tundisi e Tundisi, 2008).

No Brasil, não há regulamentação para níveis de fósforo $(\mathrm{P})$ utilizados nas rações, mas sim para níveis de efluentes gerados pela atividade aquícola. Esses valores são preconizados e estabelecidos pelo Conselho Nacional de Meio Ambiente (Conama) por meio das Resoluções n. 357, de 17 de março de 2005, e n. 413, de 26 de junho de 2009, que tratam do licenciamento ambiental da aquicultura, lançamentos de efluentes e dão outras providências quanto à prática dessa atividade (Brasil (2005/2009). Flatt et al. (2001) citaram que, nos Estados Unidos, há regulamentação para o uso de $\mathrm{P}$ na produção animal pelo fato de haver preocupação de contaminação por esta atividade.

A alimentação de peixes apresenta uma relação direta com a qualidade da água e com o impacto ambiental devido aos efluentes produzidos pelos animais cultivados. Assim sendo, a utilização de dietas balanceadas de mínimo custo e adequado manejo alimentar é requisito essencial para se obter sucesso na produção sustentável de peixes (Furuya, 2007; Cole et al., 2009; Cyrino et al., 2010).

Segundo Gyllenhammar et al. (2008) e Amirkolaie (2011), as informações sobre os requisitos de fósforo dietário para cada espécie de peixe e a disponibilidade desse nutriente nos alimentos são fundamentais para a formulação de dietas de baixo custo e que minimizem a excreção para o meio aquático. No entanto, são poucos os dados disponíveis na literatura sobre a exigência e o valor biológico dos alimentos e fontes inorgânicas de fósforo para os peixes (Mukhopadhyay e Ray, 1997), limitando, assim, nutricionistas e empresas do ramo em formular dietas com níveis mínimos e ideais de fósforo para cada espécie.

Salati et al. (2002) salientaram que há muita dificuldade em conhecer, com precisão, as cargas pontuais e difusas, tanto na quantidade como na qualidade, para fazer um balanço de massa adequado dentro dos modelos de capacidade de suporte, principalmente em ambientes de clima tropical e com espécies específicas como a tilápia-do-nilo, o pacu (Piaractus mesopotamicus), o jundiá (Rhamdia quelen), o surubim (Pseudoplatystoma sp.), e outros peixes utilizados nos sistemas produtivos brasileiros.

Para a avaliação da porcentagem de fósforo absorvido nas dietas pelos peixes e das cargas pontuais, têm-se os estudos de digestibilidade. Estes objetivam a determinação do valor nutricional de um alimento, no qual a digestibilidade depende, primeiramente, da composição química e, também, da capacidade digestiva do animal em relação ao alimento. Desse modo, sabe-se quanto é aproveitado e quanto o peixe não consegue assimilar de um 
determinado alimento ou ingrediente de uma dieta específica. Estes estudos têm sido prioridade para a nutrição na aquicultura, a fim de avaliar ingredientes ou a qualidade de dietas completas e o favorecimento do melhor aproveitamento da dieta pelos peixes (Sadiku e Juancey, 1995).

O objetivo deste estudo foi avaliar a digestibilidade de rações formuladas com diferentes porcentagens de fósforo total como estratégia nutricional para redução de efluentes gerados pela produção de juvenis de tilápia-donilo.

\section{MATERIAL E MÉTODOS}

O experimento foi aprovado pelo Comitê de Ética na Experimentação Animal da Universidade Estadual do Oeste do ParanáUnioeste/Campus de Toledo, sob o protocolo $\mathrm{n}^{\circ}$ 0110 .

Utilizou-se um lote homogêneo com 120 tilápiasdo-nilo, linhagem Chitralada, com peso médio de $85,11 \pm 0,34 \mathrm{~g}$ e comprimento total médio de $15,6 \pm 0,41 \mathrm{~cm}$, os quais foram distribuídos em seis cubas cônicas cilíndricas com capacidade de 60 litros, providas de um copo coletor na sua parte inferior, onde, após o período noturno, as fezes depositavam-se.

Em cada cuba de coleta alojaram-se 20 indivíduos, sendo que cada cuba foi considerada uma unidade experimental. Acoplou-se um aquecedor $(100 \mathrm{~W})$ para a manutenção da temperatura $\left(25^{\circ} \mathrm{C}\right)$, e um termômetro de bulbo de mercúrio auxiliava na aferição. O sistema possuía aeração individual, realizada por meio de uma pedra porosa acoplada a dispersores de ar para conservação de aproximadamente $5,0 \mathrm{mgL}^{-1}$ de oxigênio dissolvido em cada unidade experimental. Anteriormente ao início do experimento, os animais foram submetidos a um período de adaptação de 15 dias às instalações e ao manejo. Posteriormente, foram adaptados às dietas experimentais por mais sete dias. $\mathrm{O}$ período de coletas de fezes foi de cinco dias para cada ração, formando dessa maneira, uma amostra composta para cada unidade experimental.

As fezes de cada dia de coleta foram congeladas para futuras análises. $\mathrm{O}$ arraçoamento durante $\mathrm{o}$ período de adaptação e coleta realizou-se ad libitum às 08h30min, 12h00min, 13h30min, $15 \mathrm{~h} 30 \mathrm{~min}$ e $19 \mathrm{~h} 00 \mathrm{~min}$. Duas vezes ao dia procedeu-se à limpeza das cubas e à troca de $50 \%$ do volume de água à $7 \mathrm{~h} 30 \mathrm{~min}$ e $19 \mathrm{~h} 00 \mathrm{~min}$.

Os peixes foram submetidos a dois tratamentos: $\mathrm{T} 1$ com $0,8 \%$ e T2 com $1,2 \%$ de fósforo total (Ptotal) nas dietas, com seis repetições (Tab. 1). As dietas experimentais foram elaboradas com ingredientes padronizados, sendo os mais comumente empregados pelas indústrias do ramo. Esses ingredientes foram moídos e extrusados para obtenção de grânulos de diâmetro médio de $3 \mathrm{~mm}$, sendo as dietas isoproteicas e isoenergéticas, com $28 \%$ de proteína bruta e 3000kcal de ED/kg (Tab. 1).

Os coeficientes de digestibilidade aparente do fósforo foram avaliados pela metodologia indireta, utilizando-se como indicador o óxido crômico $\left(\mathrm{Cr}_{2} \mathrm{O}_{3}\right)$ segundo o NRC (Nutrient..., 1993), incorporado na proporção de $0,1 \%$ da dieta.

O cálculo dos valores dos ingredientes das dietas foi realizado por meio de cotações em empresas especializadas do ramo durante o período de estudo.

As fezes foram descongeladas, secas em estufa de circulação forçada a $55^{\circ} \mathrm{C}$ por 24 horas, peneiradas para a retirada de resíduos e moídas para as análises centesimais, segundo a metodologia descrita pela AOAC (1990).

As determinações da concentração de $\mathrm{Cr}_{2} \mathrm{O}_{3}$ nas fezes e nas rações foram determinadas por espectrofotometria de absorção atômica segundo Kimura e Miller (1957), para posterior cálculo do coeficiente de digestibilidade $(D t d)$.

Para o cálculo do Dtd na matéria seca (MS) e da disponibilidade do fósforo (Dand) seguiram as equações utilizadas por Mukhopadhyay e Ray (1997) indicadas pelo NRC (National..., 1993). 


$$
D t d=100-100\left(\frac{\% I d}{\% I f}\right) \quad \text { Dand }=100-100\left(\frac{\% I d}{\% I f} \times \frac{\% N f}{\% N d}\right) \quad \text {, em que: }
$$

$D t d$ é a digestibilidade total da dieta referência e da dieta teste (\%); Dand, a digestibilidade aparente dos nutrientes nas dietas referência e teste (\%); $I d$, o indicador na dieta; If, o indicador nas fezes; $N f$, o nutriente nas fezes e $N d$, o nutriente na dieta.

Tabela 1. Composição percentual dos ingredientes e análise físico-química das dietas experimentais utilizadas na alimentação da tilápia-do-nilo (Oreochromis niloticus) (base na matéria natural)

\begin{tabular}{|c|c|c|}
\hline \multirow{2}{*}{ Ingrediente $(\%)$} & \multicolumn{2}{|c|}{ Fósforo total (\%) } \\
\hline & $0,8 \%$ & $1,2 \%$ \\
\hline Milho grão & 38,18 & 34,10 \\
\hline Farelo de soja & 35,03 & 32,22 \\
\hline Farinha de vísceras de aves & 10,21 & 10,17 \\
\hline Farelo de trigo & 5,51 & 10,00 \\
\hline Arroz quirera & 5,00 & 5,00 \\
\hline Fosfato bicálcico & 0,00 & 1,45 \\
\hline Premix vitamínico e mineral $^{1}$ & 1,00 & 1,00 \\
\hline Sal & 0,30 & 0,30 \\
\hline Calcário calcítico & 1,50 & 0,00 \\
\hline Óleo de soja & 0,00 & 0,50 \\
\hline Farinha de carne e ossos & 3,02 & 5,00 \\
\hline DL - Metionina & 0,25 & 0,26 \\
\hline Total & 100,00 & 100,00 \\
\hline \multicolumn{3}{|l|}{ Valor calculado $^{2}$} \\
\hline Amido (\%) & 29,08 & 27,89 \\
\hline Calcário (\%) & 1,50 & 1,50 \\
\hline Energia digestível (kcal/kg) & 3000,00 & 3000,00 \\
\hline Fibra bruta $(\%)$ & 3,52 & 3,70 \\
\hline Fósforo total (\%) & 0,80 & 1,20 \\
\hline Gordura (\%) & 3,54 & 4,23 \\
\hline Lisina $(\%)$ & 1,52 & 1,50 \\
\hline Met+Cis total $(\%)$ & 1,12 & 1,13 \\
\hline Metionina (\%) & 0,70 & 0,70 \\
\hline Proteína bruta (\%) & 28,00 & 28,00 \\
\hline
\end{tabular}

${ }^{1}$ Suplemento vitamínico e mineral: Níveis de garantia por quilograma do produto: Vit. A, 24.000UI; Vit. D3, 6.000UI; Vit. E, 300mg; Vit. K3, 30mg; Vit. B1, 40mg; Vit. B2, 40mg; Vit. B6, 35mg; Vit. B12, 80mg; Ác. fólico, 12mg; Pantotenato Ca, 100mg; Vit. C, 600mg; Biotina, 2mg; Colina, 1.000mg; Niacina; Ferro,200mg; Cobre,35mg; Manganês, 100mg; Zinco, 240mg; Iodo, 1,6mg; Cobalto, 0,8mg.

${ }^{2}$ Formulação baseada nas exigências para espécie de acordo com Pezzato et al. (2002).

As variáveis físicas e químicas da água como temperatura $\left({ }^{\circ} \mathrm{C}\right), \mathrm{pH}$, condutividade $\left(\mu \mathrm{S} \mathrm{cm}^{-1}\right)$ e oxigênio dissolvido $\left(\mathrm{mg} \mathrm{L}^{-1}\right)$ foram monitoradas diariamente às $7 \mathrm{~h}$ e $30 \mathrm{mim}$ e às $15 \mathrm{~h}$, por meio de aparelhos digitais portáteis previamente calibrados. As análises de fósforo total $\left(\mathrm{mgL}^{-1}\right)$, ortofosfado $\left(\mathrm{mgL}^{-1}\right)$ e demanda bioquímica de oxigênio $\left(\mathrm{mgL}^{-1}\right)$ foram realizadas a cada cinco dias, de acordo com o proposto por Mackreth et al. (1978), Strickland e Parson (1972) e Koroleff et al. (1976), respectivamente. No cálculo da relação de diluição da água, preconizaram-se os valores obtidos neste estudo divididos pelos valores de $0,030 \mathrm{mg} \mathrm{L}^{-1}$ para ambientes lênticos e $0,050 \mathrm{mg} \mathrm{L}^{-1}$ para lóticos preconizados pelo Conama 357/2005 para emissão de efluentes em água de classe 2 .

Nas análises estatísticas aplicou-se teste de Tukey a 5\% de significância para comparação de médias, utilizando-se o programa computacional SAS (1997). 


\section{RESULTADOS E DISCUSSÕES}

Nas análises da qualidade da água observaram-se diferenças $(\mathrm{P}<0,5)$ no fósforo total, no ortofosfato, na demanda bioquímica de oxigênio, no oxigênio dissolvido e na na condutividade entre os tratamentos (Tab. 2).

A diferença na inclusão de $0,8 \%$ para $1,2 \%$ de fósforo total nas dietas contribuiu para o acréscimo nos parâmetros de qualidade da água em $0,120 \mathrm{mgL}^{-1} ; \quad 0,069 \mathrm{mgL}^{-1} ; \quad 4,963 \mathrm{mgL}^{-1} \mathrm{e}$ $10,6 \mu \mathrm{Scm}^{-1}$ para P-total, ORTO, DBO e CD, respectivamente. Segundo a Resolução 357/05 do Conama, para água de Classe 2, ambos os tratamentos apresentam valores acima do preconizado para a prática de aquicultura. $\mathrm{O}$ uso da dieta com menor porcentagem de P-total colaborou com a redução dos valores médios dos parâmetros químicos e físicos dos efluentes aquícolas, tornando-se uma estratégia a ser praticada.

Tabela 2. Valores médios do fósforo total (P-Total), ortofosfato (ORTO), demanda bioquímica de oxigênio $\left(\mathrm{DBO}_{5}\right)$, oxigênio dissolvido $\left(\mathrm{O}_{2} \mathrm{D}\right)$, condutividade $(\mathrm{CD})$, potencial hidrogeniônico $(\mathrm{pH})$ e temperatura $(\mathrm{T})$ na água do cultivo dos juvenis de tilápia, utilizando-se dois teores de fósforo total na dieta

\begin{tabular}{cccccccc}
\hline \multirow{2}{*}{ Fósforo na dieta } & \multicolumn{7}{c}{ Parâmetro } \\
\cline { 2 - 7 } & $\begin{array}{c}\text { P-total } \\
\left(\mathrm{mg} \mathrm{L}^{-1}\right)\end{array}$ & $\begin{array}{c}\text { ORTO } \\
\left(\mathrm{mg} \mathrm{L}^{-1}\right)\end{array}$ & $\begin{array}{c}\mathrm{DBO}_{5} \\
\left(\mathrm{mg} \mathrm{L}^{-1}\right)\end{array}$ & $\begin{array}{c}\mathrm{O}_{2} \mathrm{D} \\
\left(\mathrm{mg} \mathrm{L}^{-1}\right)\end{array}$ & $\begin{array}{c}\mathrm{CD} \\
\left(\mu \mathrm{cm}^{-1}\right)\end{array}$ & $\mathrm{pH}$ & $\begin{array}{c}\mathrm{T} \\
\left({ }^{\circ} \mathrm{C}\right)\end{array}$ \\
\hline T1: $0,8 \%$ & $0,216 \mathrm{~b}$ & $0,014 \mathrm{~b}$ & $5,852 \mathrm{~b}$ & $4,5 \mathrm{a}$ & $63,7 \mathrm{~b}$ & $6,72 \mathrm{a}$ & $25,4 \mathrm{a}$ \\
T2: $1,2 \%$ & $0,336 \mathrm{a}$ & $0,083 \mathrm{a}$ & $10,815 \mathrm{a}$ & $4,8 \mathrm{a}$ & $74,3 \mathrm{a}$ & $6,68 \mathrm{a}$ & $25,1 \mathrm{a}$ \\
\hline
\end{tabular}

Médias seguidas por letra distinta diferem entre si pelo teste Tukey a 5\%.

Considerando-se que o aumento de $0,4 \%$ de fósforo na ração contribuiu para o acréscimo de $55 \%$ de fósforo (Tab. 2), estimou-se a relação de diluição do fósforo na água durante o cultivo de tilápia em relação ao teor da inclusão na dieta (Tab. 3). Assim sendo, os valores obtidos correspondem ao disposto no item 6.10 da Instrução Normativa Interministerial $\mathrm{n}^{\circ} 06$, de maio de 2004, a qual preconiza uma relação de diluição da área dos tanques-rede com a área da poligonal do empreendimento entre 1:5 e 1:8 para tanques-rede e gaiolas.

Tabela 3. Estimativa de diluição do fósforo total na água dos sistemas de cultivo de tilápia em relação ao teor de fósforo na dieta

\begin{tabular}{ccc} 
Fósforo total & \multicolumn{2}{c}{ Relação de diluição } \\
\cline { 2 - 3 } na dieta & $\begin{array}{c}\text { Viveiros de } \\
\text { terra }\end{array}$ & $\begin{array}{c}\text { Tanques- } \\
\text { rede }\end{array}$ \\
\hline $0,8 \%$ & $1: 7,2$ & $1: 4,3$ \\
$1,2 \%$ & $1: 11,2$ & $1: 6,7$ \\
\hline
\end{tabular}

Relação de diluição da água calculada com base nos valores preconizados pelo Conama 357/05 para água de Classe 2.

De acordo com o observado nas Tab. 2 e 3, demonstra-se a importância da utilização dos valores de diluição no dimensionamento dos sistemas de cultivo e a adoção de menores valores de fósforo na formulação das dietas. Boscolo et al. (2003) e Boscolo et al. (2005) salientaram que a dieta com menor porcentagem de fósforo, além de resultar em melhor eficiência de utilização desse mineral por juvenis de tilápia, apresenta também menores valores de emissão de efluentes nos parâmetros de qualidade da água.

Extrapolando isso para um ambiente com pouca renovação de água, como os viveiros de terra, onde há produção de toneladas de peixe por hectare, corre-se o risco de haver uma crescente quantidade de fósforo e material nitrogenado, que pode causar afloração de algas no ambiente. No caso de reservatórios, há de se tomar mais cuidados, pois o volume de água é maior, as reações podem ocorrer na mesma intensidade e o dano poder ser irreversível. Isto ocorre principalmente em ambientes lênticos, onde há pouca renovação da água e longo tempo de retenção da água, como nos braços dos reservatórios, onde se pratica a aquicultura com tanques-rede.

Neste contexto, a utilização de dietas de maior digestibilidade e níveis adequados de fósforo para o atendimento da exigência nutricional do peixe é de extrema importância para evitar o 
acréscimo de nutrientes oriundos da piscicultura no ambiente aquático. Entretanto, deve-se salientar que os peixes, além de excretarem o fósforo, também mobilizaram mais intensamente esse mineral do ambiente a fim de manter a integridade dos processos metabólicos, o que não ocorre quando ele existe em excesso na dieta (Quintero-Pinto, 2008). Geralmente, quando as reservas orgânicas dos animais estão exauridas, ocorre o processo de bioacumulação. Este evento foi observado por Miranda et al. (2000a), os quais, ao estudarem tilápias-do-nilo, verificaram que, ao longo do cultivo, há o aumento na absorção de fósforo da água em 0,50; 0,65 e $1,06 \mathrm{mgL}^{-1}$ pelos peixes.

Furuya et al. (2008), ao estudarem a disponibilidade desse mineral para tilápia, ressaltaram que a excreção de fósforo fecal por quilo de peixe produzido aumenta linearmente entre os teores 0,$25 ; 0,35 ; 0,45$ e $0,55 \%$ de $\mathrm{P}$ disponível, comprovando a necessidade de não utilizar dietas com valores de fósforo disponível acima das exigências. A eficiência na utilização do fósforo do T1, com $74,8 \%$, e T2, com $75,3 \%$, obtida neste experimento, demonstrou que o aproveitamento desse mineral pelos peixes atingiu valores aproximados, ou seja, podem-se diminuir as porcentagens de inclusão para que haja redução do acréscimo de poluentes na água (Tab. 4).

Tabela 4. Teores de fósforo na dieta (PD), taxa de digestibilidade total da dieta $(D t d)$, taxa de digestibilidade do fósforo da dieta (Dand), e custo total da dieta (CTD) para juvenis de tilápiado-nilo

\begin{tabular}{lcc}
\hline Análise & \multicolumn{2}{c}{ Valor $(\%)$} \\
\hline PD & 0,80 & 1,20 \\
Dtd & 75,27 & 77,48 \\
Dand & 74,78 & 75,31 \\
CTD $(\mathrm{R} \$ / \mathrm{kg})$ & 0,72 & 0,75 \\
\hline
\end{tabular}

A redução dos níveis de fósforo na ração é uma estratégia que pode ser utilizada com eficiência, sem prejudicar o desempenho zootécnico dos animais, pois estudos demonstram que a exigência de fósforo para a tilápia apresenta uma faixa de valores menores do que os praticados pela indústrias de ração brasileiras, as quais utilizam teores acima de 1,0\% de P-total nas dietas, principalmente pelo fato de serem utilizadas fontes proteicas de origem animal com elevado teor de cinzas (Furuya et al., 2008).

Watanabe et al. (1988), ao avaliarem tilápias com peso de 0,6 a 33,65g, concluíram que a exigência de $\mathrm{P}$ está entre 0,8 e 1,0\%. O NRC (National..., 1993) cita a utilização de $0,5 \%$ de $\mathrm{P}$ disponível. Miranda et al. (2000b) avaliaram $O$. niloticus com peso de 2,5 a 43,61g e recomendaram o $\mathrm{P}$ disponível entre 0,5 e $0,75 \%$. Boscolo et al. (2003) e Boscolo et al. (2005) estudaram essa espécie com pesos entre 23 e $89 \mathrm{~g}$ e 0,95 e $12,52 \mathrm{~g}$ e verificaram níveis de exigência de 0,35 a 0,70 e $0,74 \%$ de fósforo, respectivamente. Ribeiro et al. (2006) concluíram que, em dietas para alevinos de tilápia-do-nilo, a necessidade de suplementação é de $1,10 \%$. Furuya et al. (2008) citaram que a exigência de fósforo disponível para essa espécie, com peso de 35 a $100 \mathrm{~g}$, é de $0,48 \%$. Contudo, aconselha-se a utilização de valores inferiores a $0,8 \%$ de fósforo total na dieta de juvenis de tilápia.

Vale ressaltar que essas diferentes exigências de fósforo encontradas para a mesma espécie pode estar relacionada à forma de processamento da ração, à fonte e à quantidade de fósforo disponibilizado na dieta, bem como à qualidade do ingrediente, as quais irão influenciar na disponibilidade e, consequentemente, no volume excretado pelos peixes.

Neste estudo, a digestibilidade do fósforo da dieta (Dand) apresentou valores de 74,8 e 75,3\% para $\mathrm{T} 1$ e $\mathrm{T} 2$, respectivamente. Tal fato demonstra a eficiência na utilização desse nutriente nos tratamentos avaliados. Hepher (1988) salientou que muitos minerais são exigidos em pequenas quantidades e as exigências podem ser atendidas pela quantidade presente na água que é absorvida por meio das brânquias.

Segundo Mukhopadhyay e Ray (1997), as fontes inorgânicas de P, como as farinhas de ossos e carne, vísceras de aves, resíduos da filetagem de peixes, entre outras, são de alta disponibilidade. No caso das fontes de origem vegetal, grande parte do fosfato presente nos vegetais não é aproveitada pelos animais por este estar ligado ao ácido fítico, o que resulta em menor eficiência na utilização do fósforo para os peixes (Jobling, 1994). Uma forma de diminuir a excreção no 
ambiente aquático e aumentar a assimilação desse mineral das fontes vegetais das dietas baseia-se na adição de fitase, enzima que aumenta a biodisponibilidade do elemento (Furuya et al., 2000; Quintero-Pinto, 2008).

Um fator limitante para a formulação e utilização dessas dietas refere-se ao custo dos ingredientes, que influenciará no valor final do produto. Os aquicultores, com o intuito de diminuir os custos com rações e ingredientes, que podem representar 60\% ou mais (Gonçalves, 2007) do custo total da exploração, utilizam rações mais baratas, encontradas no mercado. Dessa forma, optam pelo menor valor, não considerando a qualidade dos ingredientes e o impacto ambiental que elas podem causar ao ambiente (Tab. 2). Além da piora na conversão alimentar, que acarretará um maior tempo para atingir o ganho de peso, haverá aumento do tempo de arraçoamento e da quantidade de fósforo acumulada no ambiente aquático.

Observa-se na Tab. 4 que a relação custo/benefício nem sempre segue essa lógica. A dieta com menor porcentagem de fósforo total apresentou menor custo e melhor eficiência de utilização do fósforo pelos juvenis de tilápia, bem como proporcionou menores valores de emissão de efluentes nos parâmetros de qualidade da água (Tab. 2). Estudos dessa natureza possibilitam a determinação de teores mínimos de fósforo e o auxílio na formulação de dietas adequadas aos peixes, diminuindo resíduos oriundos da aquicultura para o ambiente aquático. A avaliação da digestibilidade e excreção das dietas é uma ferramenta adequada para garantir a inocuidade ambiental dos cultivos aquícolas. Esta questão não envolve apenas o aspecto ambiental, reflete diretamente na viabilidade da atividade que, cada vez mais, é um dos principais desafios para a prática da aquicultura sustentável (Valenti, 2002; Pillay, 2007).

\section{CONCLUSÃO}

A utilização da dieta com disponibilidade de $0,8 \%$ de fósforo total promove melhor controle da qualidade da água e pode ser utilizada como estratégia na formulação de dietas para diminuição de efluentes da aquicultura.

\section{AGRADECIMENTOS}

Ao Grupo de Estudos de Manejo em Aquicultura/Gemaq, pelo apoio de laboratórios e estruturas de pesquisa, e à Coordenação de Aperfeiçoamento Pessoal de Nível Superior/ Capes, pelo apoio financeiro.

\section{REFERÊNCIAS}

AMIRKOLAIE, A.K. Reduction in the environmental impact of waste discharged by fish farms through feed and feeding. Rev. Aquacult., v.3, p.19-26, 2011.

ALVES, R.C.P.; BACCARIN, A.L. Efeitos da produção de peixes em tanques-rede sobre sedimentação de material em suspensão e de nutrientes no Córrego da Arribada (UHE Nova Avanhandava), baixo Rio Tietê. In: NOGUEIRA, M.G.; HENRY, R.; JORCIN, A. (Org.). Ecologia de reservatórios: impactos potenciais, ações de manejo e sistemas em cascata. São Carlos: Rima, 2005. p.329-347.

ASSOCIATION OF OFFICIAL ANALYTICAL CHEMISTS - AOAC. Official methods of analysis. v.1, 15 ed. Washington, D.C.: 1990. $1117 \mathrm{p}$.

BOSCOLO, W.R.; FEIDEN, A.; REIDEL, A. et al. Exigências de fósforo da tilápia-do-nilo (Oreocrhomis niloticus) na fase de crescimento. Varia Scient. Agrária, v.3, p.115-124, 2003.

BOSCOLO, W.R.; FEIDEN, A.; BOMBARDELLI, R.A. et al. Exigências de fósforo para alevinos de tilápia-do-nilo (Oreochromis niloticus). Acta Scient. Anim. Sci., v.27, p.87-91, 2005.

BRASIL. Conselho Nacional de Meio Ambiente. Resolução Conama no 357, de 17 de março de 2005. Dispõe sobre a classificação dos corpos de água e diretrizes ambientais para o seu enquadramento, bem como estabelece as condições e os padrões de lançamento de efluentes, e dá outras providências. Disponível em: <http://www.mma.gov.br/port/conama/res/res05/res35 705. pdf>. Acessado em: 15 mar. 2010.

BRASIL. Conselho Nacional de Meio Ambiente. Resolução $n^{o} 413$, de 26 de junho de 2009 Dispõe sobre o licenciamento ambiental da aquicultura e dá outras providências. Disponível em: <http://www.mma.gov.br>. Acessado em: 6 fev. 2010. 
BRASIL - MINISTÉRIO DA PESCA E AQUICULTURA. 2010. Estatística da Pesca e Aquicultura no Brasil 2008/2009. Disponível em: <http://www.mpa.gov.br/\#infoestatistica/estatistica-da-pesca-e-aquicultura> Acessado em: 25 nov. 2010.

COLE, D.W.; COLE, R.; GAYDOS, S.J. et al. Aquaculture: Environmental, toxicological, and health issues. Int. J. Hyg. Environ. Health., v.212, p.369-377, 2009.

CYRINO, J.E.P.; BICUDO, A.J.A.; SADO, R.Y. et al. A piscicultura e o ambiente - o uso de alimentos ambientalmente corretos em piscicultura. Rev. Bras. Zootec., v.39, supl. especial, p.68-87, 2010.

FARIA, A.C.E.A.; HAYASHI, C.; SOARES, C.M. Farinha de vísceras de aves em rações para alevinos de tilápia-do-nilo, Oreochromis niloticus (L.). Rev. Bras. Zootec., v.31, supl., p.812-822, 2002.

FLATT, W.R.; STANTON, T.L.; SCHULTZ, D. et al. Effect of phosphorus concentration on blood serum phosphorus concentration, growth performance, carcass characteristics and cost of gain on finishing cattle. Animal Sciences Research Report. 2002. Disponível: <http://ansci.colostate.edu/ran/beef/wrf012.htm> . Acessado em: 12 fev. 2010.

FURUYA, W.M.; HAYASHI, C.; FURUYA, V.R.B. et al. Exigência de proteína para alevino revertido de tilápia-do-nilo (Oreochromis niloticus). Rev. Bras. Zootec, v.29, p.1912-1917, 2000.

FURUYA, W.M.; FUJII, K.M.; DOS SANTOS, L.D. et al. Exigência de fósforo disponível para tilápia-do-nilo (35 a 100g). Rev. Bras. Zootec., v.37, p.961-966, 2008.

GODINHO, H.P. Estratégias reprodutivas de peixes aplicadas à aquicultura: bases para $\mathrm{O}$ desenvolvimento de tecnologias de produção. Rev. Bras. Reprod. Anim., v.31, p.351-360, 2007.

GONÇALVES, G.S. Digestibilidade e exigência de lisina, proteína e energia em dietas para tilápia-do-nilo. 2007. 98f. Tese (Doutorado) Centro de Aquicultura da Unesp, Universidade Estadual Paulista, Jaboticabal, SP.
GYLLENHAMMAR, A.; HAKANSON, L.; LEHTINEN, KARL-JOHAN. A mesocosm fish farming experiment and its implications for reducing nutrient load on a regional scale. Aquacult. Eng., v.38, p.117-126, 2008.

HEPHER, B. Nutrition of pond fishes. Cambridge, Inglaterra: Cambridge University, 1988. 406p.

JOBLING, M. Fish Bioenergetics. Fish and Fisheries. Series 13. London: Chapman \& Hall Eds. 1994. 309p.

KIMURA, F.T.; MILLER, V.L. Improved determination of chromic oxide in cal feed and feces. J. Agric. Food Chem., v.5, p.216, 1957.

KOROLEFF. Determination of nutrients. In: GRASSHOFF, K. Methods of sea wateranalysis. Verlag Chemie Weinhein, 1976. 181p.

MACKERETH, J.F.H.; HERON, J.; TALLING, J.F. Water analysis: some revised methods for limnologists. Fresh. Biol. Assoc., n. 36, p.121, 1978.

MIRANDA, E.C.; PEZATTO, C.A.; PEZZATO, L.E. et al. Disponibilidade aparente de fósforo em ingredientes pela tilápia-do-nilo (Oreochromis niloticus). Acta Scient., v.22, p.669-675, 2000a.

MIRANDA, E.C.; PEZZATO, A.C.; PEZZATO, L.E.; et al. Relação cálcio/fósforo disponível em rações para tilápia do Nilo (Oreochromis niloticus). Rev. Bras. Zootec., v.29, p.2162-2171, 2000b.

MUKHOPADHYAY, N.; RAY, A.K. The apparet total and nutrient digestibility of sal seed (Shorea robusta) meal in rohu, (Labeo rohita), fingerlings. Aquacult. Res., v.28, p.683-689. 1997.

NEVES, P.R.; NATALI, M.R.M.; RIBEIRO, R.P; et al. Morphological characteristics of ovarian development of two Nile tilapia (Oreochromis niloticus) strains in mixed-culture systems. Arq. Bras. Med. Vet. Zootec., v.61, p.1173-1182, 2009.

NATIONAL RESEARCH COUNCIL - NRC. Nutrient requirements of fish. Washington, Committee on Animal Nutrition: Board on Agriculture, 1993. 114p. 
ODUM, E. P.; BARRETT, G.W. Fundamentos da Ecologia. Thompson Pioneira, 5.ed, 2007. $612 \mathrm{p}$.

PEZZATO, L.E. MIRANDA, E.C.; BARROS, M.M. et al. Digestibilidade aparente de ingredientes pela tilápia-do-nilo (Oreochromis niloticus). Rev. Bras. Zootec., v.31, p.1595-1604, 2002.

PILLAY, T. References and Further Reading, in Aquaculture and the Environment. 2.ed. Oxford: Blackwell, 2007. 188p.

QUINTERO-PINTO, L.G. Digestibilidade aparente de nutrientes e disponibilidade de fosfatos inorgânicos, pela tilápia-do-nilo (Oreochromis niloticus) em três fases de desenvolvimento. 2008. Tese (Doutorado) Faculdade de Medicina Veterinária e Zootecnia, Universidade Estadual Paulista, Botucatu, SP.

RIBEIRO, F.B.; LANNA, E.A.T.; BOMFIM, M.A.D. et al. Níveis de fósforo total em dietas para alevinos de tilápia-do-nilo. Rev. Bras. Zootec., v.35, supl., p.1588-1593, 2006.

SADIKU, S.O.E.; JAUNCEY, K. Digestibility apparent amino acid avaliability and waste generation potential of soybean flour: poultry meat blend based diets for tilapia, Oreochromis niloticus, fingerling. Aquacult. Res., v.26, p. 651657, 1995.

SALATI, E.; LEMOS, H.M.; SALATI, E. Água e o desenvolvimento sustentável. In: REBOUÇAS, A.C.; BRAGA, B.; TUNDISI, J.G.
Águas doces no Brasil: capital ecológico, uso e conservação. 2.ed. São Paulo: Escrituras Editora, 2002. p. 39-63.

SAS. SAS/STAT software: changes and enhancements through release 6.12. Cary: Statistical Analysis System Institute, 1997. 1167p.

STICKNEY, R.R. Tilapia nutrition feeds and feeding. In: COSTA-PIERCE, B.A.; RAKOCY, J.E. (Eds.) Tilapia Aquaculture in the Americas. Baton Rouge: The World Aquaculture Society \& The American Tilapia Association, 1997. v.1, p.34-54.

STRICKLAND, J.D.H.; PARSONS, T.R. A pratical handbook of seawater analysis. Ottawa: Fish. Res. Board of Canada,1972. 310p.

TUNDISI, J.G.; TUNDISI, T.M. Limnologia. São Paulo: Oficina de Textos, 2008. 631p.

VALENTI, W. C. Aquicultura sustentável. In: CONGRESSO DE ZOOTECNIA, 12., Vila Real, Portugal, 2002. Vila Real: ASSOCIAÇÃO PORTUGUESA DOS ENGENHEIROS ZOOTÉCNICOS. Anais... 2002, p.111-118.

WATANABE, T.; SATOH, S.; TAKEUCHI, T. Availability of minerals in fish meal to fish. Asian Fish. Sci., v.1, p.175-195, 1988. 